\title{
Desenvolvimento e projeto de colhedora de babaçu (Orbignya phalerata Mart.) para agricultura familiar nas regiões de matas de transição da Amazônia
}

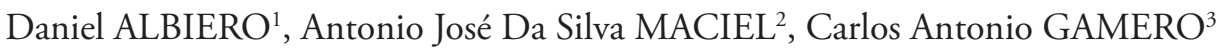

\begin{abstract}
RESUMO
O babaçu (Orbignya phalerata) é uma típica palmeira das matas de transição dos ecossistemas Amazônia/Cerrado e Amazônia/ Caatinga, sendo de grande importância econômica, social e ambiental nestas regiōes. Os produtos advindos dos babaçuais possibilitam renda para uma das camadas mais pobres da região amazônica e um dos entraves para a obtenção eficiente destes produtos é a colheita dos cocos de babaçu, que atualmente se faz no sistema extrativista. O objetivo deste trabalho foi realizar o desenvolvimento e projeto de uma colhedora de babaçu adaptável ao ambiente de trabalho da agricultura familiar e as características das matas de transição amazônicas. Para tal foram realizados estudos de literatura que nortearam as decisões e simplificaçóes de projeto, assim como foram realizados os cálculos e desenhos da nova colhedora. O projeto foi realizado através de ferramentas de engenharia que apresentaram como resultados o memorial de cálculo que descreve o caminho técnico para o dimensionamento dos elementos constituintes da colhedora e a partir destes os desenhos detalhados dos elementos da nova máquina. Pelos desenhos detalhados suas consideraçôes e decisóes concluí-se que a colhedora de babaçu apresenta-se passível de ser construída com materiais nacionais de baixo custo, além de fácil operação, manutenção e com mínimo efeito sobre os babaçuais naturais.
\end{abstract}

PALAVRAS-CHAVE: Babaçu; Projeto de Máquinas; Colhedora.

\section{Design and development of babaçu (Orbignya phalerata Mart.) harvest for small farms in areas of forests transition of the Amazon}

\section{ABSTRACT}

The babaçu (Orbignya phalerata) is a typical palm of transition forests of Amazon/Savana and Amazon/Caatinga econsystems; it is very important economically, socially and environmentally in this region. Products derived from babaçu provide income for the poor of these regions. One of the problems for obtaining this product efficiently is the extractivist system of harvesting. The objective of this work is to set up a self-propelling project of babaçu harvesting, for family farmers of the Amazonian transition forest region, which would not interfere in natural babaçu forests, and would contribute to harvesting efficiency. The project was carried out with engineering tools. We obtained the calculus memorial, definition of machine elements, which substantiates the technical of the project.

KEYWORDS: Babaçu; Machine Project; Harvest Machine.

1 Universidade Estadual de Campinas.E-mail: daniel.albiero@gmail.com

2 Universidade Estadual de Campinas.E-mail: amaciel@agr.unicamp.br

${ }^{3}$ Universidade Estadual Paulista Júlio de Mesquita Filho.E-mail: gamero@reitoria.unesp.br 


\section{INTRODUÇÃO}

O babaçu destaca-se entre as palmeiras encontradas em território brasileiro pela peculiaridade, graça e beleza da estrutura que lhe é característica, chega a atingir 20 metros de altura, suas folhas mantêm-se em posição retilínea, pouco se voltando em direçáo ao solo; orientando-se para o alto, o babaçu tem o céu como sentido, o que lhe dá uma aparência altiva (USP, 2006). O babaçual é um dos sistemas ecológicos amazônicos com maior potencial econômico, social e ambiental e é nativo da zona de transição entre o cerrado e as florestas abertas do sul da Amazônia, onde invadiu áreas perturbadas pelo homem e formou populaçôes oligárquicas (Clement et al., 2005). Clement et al. (2005) afirma que todo o babaçu é produzido pela população pobre da região amazônica por absoluta falta de outras oportunidades.

Percebe-se pela Figura 1, que os babaçuais margeiam toda a área entre a Amazônia fitogeográfica e o cerrado brasileiro, desde o cerrado motogrossence até o maranhense, em relaçáo à caatinga, os babaçus predominam na região de interface entre a caatinga nordestina e a Amazônia, região esta sobre o Estado do Maranhão, além de estarem presentes em todas as ilhas de caatinga amazônica dispersas na Amazônia geográfica.

O Estado do Maranhão participa, em média, com cerca de $65 \%$ da área nacional de ocorrência do babaçu, o que representa 30\% da superfície do Estado (Ferreira, 1999). A distribuiçẫo de babaçus no Estado do Maranhão é apresentada na Figura 1.

O babaçu é uma cultura assentada em base familiar, principalmente esteiada na mulher, portanto dentro do contexto da agricultura familiar brasileira (Albiero et al. 2007). Os produtos alimentares provenientes do babaçu podem contribuir significativamente para a segurança alimentar da região amazônica onde ocorrem, já que a Amazônia é detentora de grande variedade alimentos que deveriam representar adequado padrão de saúde para sua população (Alencar, et al. 2007).
As palmeiras de babaçu e os seus sistemas de produção agrícola regionais estão intimamente ligados na zona de babaçu, de uma maneira que pode ser descrita como práticas agroflorestais (May, 2000). A floresta amazônica está sendo derrubada de forma acelerada porque tem pouco valor na percepçáo da sociedade brasileira atual (Clement \& Higuchi, 2006). Albiero et al. (2007) afirma que um sistema de colheita que se adapte a florestas naturais possibilitará a diminuição das queimadas e derrubadas dos babaçuais, que é um grave problema ambiental e legal devido à devastação que causam e as leis que as proíbem.

Neste trabalho devido a estudos mais detalhados da literatura e a consideraçóes técnicas do anteprojeto, pretendeuse alcançar avanços através de modificaçôes em um conceito inicial de colhedora de babaçu proposto por Albiero et al. (2007), apresentado na Figura 2.

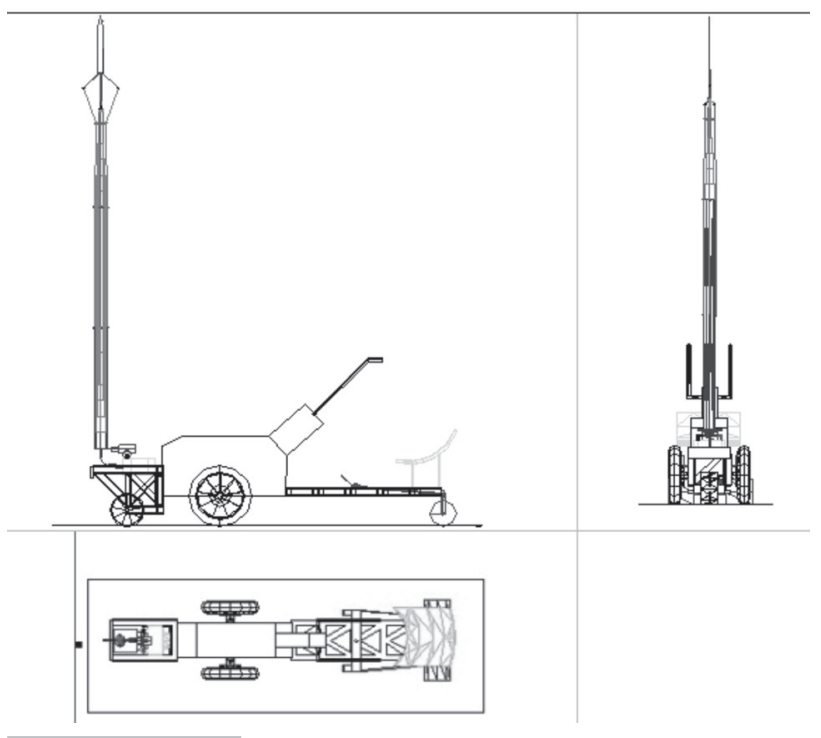

Figura 2 - Colhedora de babaçu proposta por ALBIER0 et al. (2007).

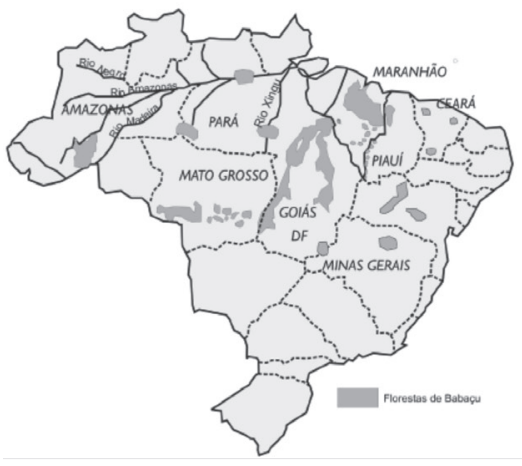

(a)

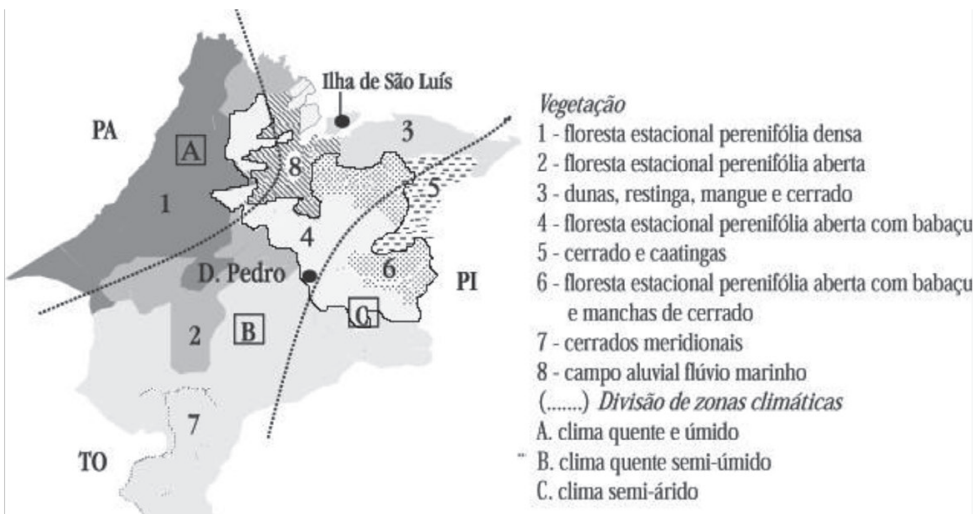

(b)

Figura 1 - (a) Distribuição geográfica dos babaçuais no Brasil (NASCIMENTO, 2004), (b) Mapa do Estado do Maranhão mostrando as fitorregiões, a área demarcada representa os babaçuais (Leonardo \& Rebelo, 2004). 
A maior força de trabalho nos babaçuais é das mulheres, que por natureza náo tem a mesma força física que os homens, o que prescindiu a modificação do sistema de corte da nova máquina. No conceito original a energia necessária ao corte seria proveniente da potência humana que acionaria um sistema de cabos para acionar a lâmina de corte. Pretendeu-se projetar a nova colhedora com um sistema de corte elétrico que possibilite muito menos desgaste para o operador.

Hueck (1972) descreve o babaçu como uma planta higrófila, portanto seu habitat é em regiáo onde o solo tem grande umidade, o que significa que um sistema convencional de rodas como o escolhido por Albiero et al. (2007) náo teria bom desempenho, sendo provável que a máquina afundasse no solo, impossibilitando a operaçáo, e nos locais onde conseguisse operar, geraria grande compactação, neste enfoque pretendeu-se projetar um sistema de esteira para a locomoção da máquina em solo úmido, minimizando a compactação e otimizando o rolamento.

Outro ponto relativo à umidade do solo e a pouca área de manobra dentro de uma floresta é sistema de direção, que no conceito original não desempenharia sua funçáo conforme o necessário, visto o escorregamento das rodas de direção traseiras, devido o pouco apoio sobre o solo, sendo necessário grande suporte da direção para realizar curvas instantâneas sem patinagem, condição imprescindível em áreas de pouco espaço e úmidas, assim pretendeu-se projetar um sistema de discos guias para melhorar a dirigibilidade da máquina, no entanto o esforço para ao operador seria excessivo, pois teria que guiar os discos com os pedais o que demandaria muita força, desta forma foram projetados pistōes hidráulicos para suprirem tal força.

A grande altura que o sistema de corte tem que ser elevado gera um sério problema de deslocamento do centro de gravidade da máquina em operaçáo, o que perfaz o risco de tombamento da mesma, pois muito facilmente o centro de gravidade sairá da área de equilíbrio limitada pelas rodas da máquina conceituada originalmente, para resolver este problema pretendeu-se projetar um sistema de manutenção de equilíbrio formado por pistôes hidráulicos que apóiam no solo patas de aço aumentando drasticamente o polígono de equilíbrio.

O objetivo deste trabalho foi realizar o desenvolvimento e projeto de uma colhedora de babaçu adaptável ao ambiente de trabalho da agricultura familiar e as características das matas de transição amazônicas. Para tal foram realizados estudos de literatura que nortearam as decisóes e simplificaçôes de projeto, assim como foram realizados os cálculos e desenhos da nova colhedora.

\section{MATERIAL E MÉTODOS}

\section{Área de Estudo, Densidade e abundância de babaçus}

A área deste estudo foi na foz do rio Mearin onde desemboca o rio Grajaú no Estado do Maranhão (coordenadas geográficas aproximadas: latitude $03^{\circ} \mathrm{S}$; longitude $45^{\circ} \mathrm{W}$ ), é predominantemente formada por solos hidromórficos com lençol freático próximo a superfície na maior parte do ano, tais como o plintossolo com textura areno-franco argilosa, considerado como pior situaçáo para capacidade suporte da máquina. Os principais tipos de solo da regiáo onde ocorrem babaçus no estado do Maranhão são apresentados na Figura 3.

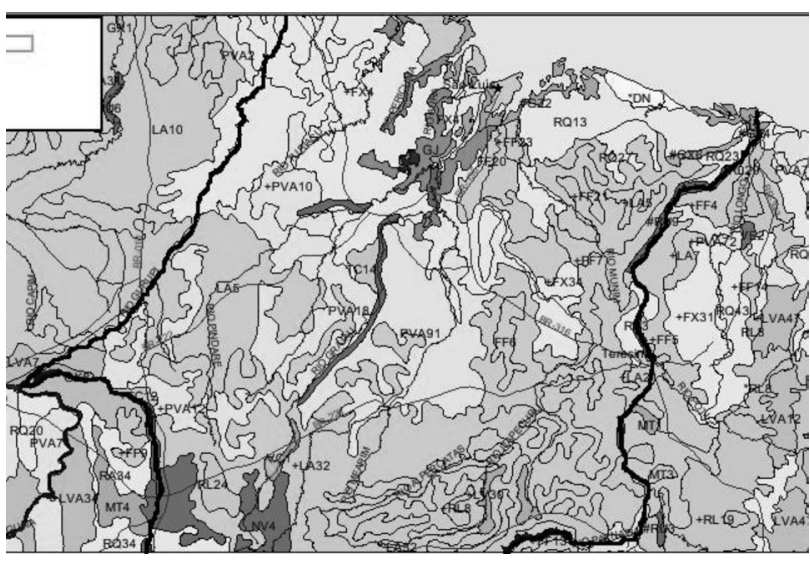

Figura 3 - Mapa parcial de solos do Estado do Maranhão, IBGE (2008). PVA: Argilossolo vermelho amarelo; LV: Latossolo Vermelho; LA: Latossolo Amarelo; FX: Plintossolo Háplico; FF: Plintossolo Pétrico; RL: Neossolo Quartzarênico; RQ: Neossolo Litólico; RU: Neossolo Flúvico; DN: Dunas; VC: Vertissolo Cromado; NV: Nitossolo Vermelho; GJ: Gleissolo Tiomórfico; GX: Gleissolo Háplico; GZ: Gleissolo Sálico; TC: Luvissolo Crômico, EMBRAPA (1999).

Segundo Ferreira (1999) a abundância de babaçus na matas onde se desenvolvem varia de 1 a 4000 plantas por hectare, tendo como média 1111 plantas por hectare. Se for considerado um cenário de exploraçáo sustentável de uma floresta virgem, ou seja, em melhores condiçôes de vida e trabalho da populaçáo e aumento da produtividade com cuidado na preservação da floresta, tem-se uma quantidade de plantas produtivas de 160 por hectare.

Ferreira (1999) afirma que qualquer comunidade ecológica com abundâncias intermediárias e poucas espécies com abundâncias muito altas ou muito baixas seguem aproximadamente uma distribuição log-normal, uma vez que abundâncias relativas de conjuntos grandes e heterogêneos de espécies tendem a serem governados por muitos fatores independentes e assim de acordo com o Teorema Central do Limite da Estatística, serão log-normalmente distribuídos. 
Foi feita uma analogia entre a abundância de babaçus prescrita no excelente trabalho de Ferreira (1999) e a distribuiçấo espacial de plantas em um babaçual.

Levando-se em conta a média de 1111 plantas por hectare, tem-se um valor de 1 planta a cada $9 \mathrm{~m}^{2}$, considerando 160 plantas produtivas por hectare, tem-se um valor de $62,5 \mathrm{~m}^{2}$ por planta produtiva, portanto na área necessária para se encontrar 1 planta produtiva existem aproximadamente 7 babaçus, no entanto esta distribuição não é homogenia, ou seja, em 1 hectare não existem 7 babaçus a cada $62,5 \mathrm{~m}^{2}$, mas sim regiōes com muito menos plantas e outras regiōes com muito mais plantas, neste trabalho a suposiçấo é que a distribuição segue um padrão log-normal.

Consideração muito importante é a densidade limite de plantas, para uma máquina do porte de um motocultor acoplado a um implemento $\left(3 \mathrm{~m}^{2}\right)$ se locomover e manobrar dentro de uma floresta. Em termos operacionais para ocorrer segura margem para manobras dentro de um talhão de floresta impor-se-á uma densidade limite de 0,3 plantas por $\mathrm{m}^{2}$, ou 1 planta para cada $3,3 \mathrm{~m}^{2}$.

\section{Capacidade de suporte do solo}

Dias Junior et al. (2007) em seu ótimo trabalho afirma que a máxima pressão que deve ser aplicada a um solo sem que haja compactação é a pressão de pré-consolidação, definida por Mitchell (1993) como a tensão pela qual um solo foi consolidado, sendo esta tensão efetiva "passada" maior do que a tensão efetiva "atual", um dos motivos para tal pré-consolidação é a dissecaçẫo periódica ocasionada pela evaporaçấo, encontrada em crostas secas de depósitos deltaicos.

Segundo Dias Junior et al. (2007) a pré-consolidação segue um modelo:

$$
\sigma_{p}=10^{(a+b U)} \quad \text { Equação } 1
$$

Onde: $\sigma_{\mathrm{p}}$ é a tensão de pré-consolidação $(\mathrm{kPa})$;

$$
\text { a e b constantes relativas ao solo; }
$$

Como limite extremo para a colhedora de babaçu foi considerado que a colheita deve ser realizada com alto teor de água no solo, sendo escolhido um plintossolo com textura areno-franco argilosa, pois é um solo hidromórfico, portanto com grande chance de ficar boa parte do ano úmido, nestas condições Dias Junior et al. (2007) encontrou a seguinte equação para a pré-consolidação para um plintossolo com densidade de $1,4 \mathrm{~kg} / \mathrm{m}^{3}$, com coeficiente de correlação de 0,87 :

$$
\sigma_{p}=10^{(2,88-3,95 U)} \quad \text { Equação } 2
$$

Com base neste modelo foi possível encontrar os valores de tensão de pré-consolidação em função dos teores de umidade:
Tabela 1 - Tensão de pré-consolidação de plintossolo em função do teor de água.

\begin{tabular}{lc}
\hline Teor de água $(\mathrm{kg} / \mathrm{kg})$ & $\mathrm{S}_{\mathrm{p}}(\mathrm{kPa})$ \\
\hline 0 & 758 \\
0,1 & 305 \\
0,2 & 123 \\
0,3 & 49 \\
0,4 & 19 \\
0,5 & 8 \\
\hline
\end{tabular}

$\mathrm{O}$ afundamento das esteiras no solo escolhido foi obtido através do modelo descrito por Upadhyaya et al. (1994):

$$
P=\left(\frac{k c}{b}+k \phi\right) * z^{n} \quad \text { Equação } 3
$$

Onde: $\mathrm{P}$ é a pressão sobre o solo $(\mathrm{N})$;

$\mathrm{kc}$, kf e n são parâmetros do solo;

b é a largura da área carregada $(\mathrm{cm})$;

$\mathrm{z}$ é o afundamento $(\mathrm{cm})$.

Para um solo franco arenoso tem-se os seguintes valores, Tabela 2, para os parâmetros do solo a uma densidade do solo de $1,48 \mathrm{~kg} / \mathrm{m}^{3}$ :

Tabela 2 - Parâmetros do solo para afundamento dos rodados em função da umidade.

\begin{tabular}{lccc}
\hline Teor de água $(\mathrm{kg} / \mathrm{kg})$ & $\mathrm{n}(\mathrm{N} . \mathrm{cm})$ & $\mathrm{kc}(\mathrm{N} . \mathrm{cm})$ & $\mathrm{kf}(\mathrm{N} . \mathrm{cm})$ \\
\hline 0 & 0,51 & - & - \\
0,1 & 0,51 & 125 & 61 \\
0,2 & 0,51 & 84 & 24 \\
0,3 & 0,51 & 8 & 3 \\
0,4 & 0,51 & 1 & 0,5 \\
0,5 & 0,51 & 0 & 0 \\
\hline
\end{tabular}

\section{Sistema de Corte e Material de estudo:}

O cálculo do sistema de corte foi realizado seguindo metodologia descrita por Persson (1987), onde a força específica necessária para o corte do material biológico (FOCS) é dada pela fórmula:

$F O C S=\left(\left(\left(\frac{M a{ }^{*} V^{*} L H M}{L T C-L W C^{*} \tan (A N O)}\right)+\left(F O B^{*} L H c u\right) * \frac{1}{L H c u}\right) * \frac{1}{L W C} \quad\right.$ Equação 4

Onde: Ma é a massa do pendúculo + cacho de babaçu (kg)-26 kg (Teixeira, 2002);

V é a velocidade da lâmina $(\mathrm{m} / \mathrm{s})-10 \mathrm{~m} / \mathrm{s}$ (Pearson,

1987);

LHM é a altura do centro de gravidade do cacho (m)-Figura 4; 
LWC é a espessura da lâmina $(\mathrm{mm})-1,5 \mathrm{~mm}$ (Catálogo Still, 2008); Still, 2008);

ANO é o ângulo da lâmina (graus)- $83^{\circ}$ (Catálogo

LTC é a espessura do material a ser cortado, pendúculo (mm)- $58 \mathrm{~mm}$ (análise de cachos reais);

LHcu é a altura de corte, abaixo da base do pendúculo e a árvore $(\mathrm{m})-606 \mathrm{~mm}$ (análise de cachos reais);

FOB é a resistência a flexão à altura de corte $(\mathrm{N})$;

FOCS é a força específica de corte $(\mathrm{N} / \mathrm{mm})$.

O volume aproximado do cacho de babaçu foi calculado em função de densidade segundo Teixeira (2002) que descreve que as densidades médias do babaçu são: do mesocarpo $=582 \mathrm{~kg} /$ $\mathrm{m}^{3}$; endocarpo $=506 \mathrm{~kg} / \mathrm{m}^{3}$ e castanha (endocarpo+amêndoa) $=564 \mathrm{~kg} / \mathrm{m}^{3}$, assim obteve-se um valor aproximado de 45 litros. Com este valor e através de uma foto de um cacho de babaçu em escala, foi possível realizar o desenho vetorial do cacho, a partir do qual o AutoCad realizou os cálculos e encontrou a posição do CG do cacho de babaçu, Figura 4.

O módulo de elasticidade do babaçu segundo Emmerich (1987) é de $2 \mathrm{GPa}$, já o módulo de elasticidade do cocos nussiferas é de 2,8 GPa segundo (Savastano Junior et al., 1997) o que justifica a possibilidade de se utilizar o mesmo valor de resistência. A resistência à ruptura das fibras do coco nussifera é de $220 \mathrm{MPa}$ (Morais et al. 2006).

Considerando que uma motoserra comum tem uma taxa de corte de em galhos finos (até $30 \mathrm{~mm}$ de diâmetro) de 20 $\mathrm{mm} / \mathrm{s}$, e que o passo entre os elos da corrente de corte é de 1 polegada $(25,4 \mathrm{~mm})$, levando-se em conta uma velocidade linear da corrente de $10 \mathrm{~m} / \mathrm{s}$ tem-se uma média de 39 golpes por segundo, assim em cada passe do elo $0,5 \mathrm{~mm}$ do pendúculo é cortado, entấo se têm os seguintes dados:
Tabela 3 - Características do corte da lâmina de um elo da corrente da Stihl Duromatic $50 \mathrm{~cm}$, para pendúculo de babaçu.

\begin{tabular}{lccccc}
\hline $\begin{array}{l}\text { Resistência } \\
\begin{array}{l}\text { a Ruptura } \\
(\mathrm{MPa})\end{array}\end{array}$ & $\begin{array}{c}\text { Resistência } \\
\text { a Ruptura } \\
\left(\mathrm{N} / \mathrm{m}^{2}\right)\end{array}$ & $\begin{array}{c}\text { Largura } \\
\text { da lâmina } \\
(\mathrm{m})\end{array}$ & $\begin{array}{c}\text { Altura do } \\
\text { corte da } \\
\text { lâmina }(\mathrm{m})\end{array}$ & $\begin{array}{c}\text { Área de } \\
\text { Corte da } \\
\text { lâmina }\left(\mathrm{m}^{2}\right)\end{array}$ & $\begin{array}{c}\text { FOB } \\
(\mathrm{N})\end{array}$ \\
\hline 220 & 220000000 & 0,0015 & 0,001 & 0,0000015 & 330 \\
\hline
\end{tabular}

Tabela 4 - Cálculo da força de corte necessária para cada passe do elo da corrente cortar $0,5 \mathrm{~mm}$.

\begin{tabular}{lccccccccc}
\hline $\begin{array}{l}\text { ANO } \\
\text { (graus) }\end{array}$ & $\begin{array}{c}\text { MA } \\
(\mathrm{kg})\end{array}$ & $\begin{array}{c}\text { VLK } \\
(\mathrm{m} / \mathrm{s})\end{array}$ & $\begin{array}{c}\text { LHM } \\
(\mathrm{m})\end{array}$ & $\begin{array}{c}\text { LWC } \\
(\mathrm{mm})\end{array}$ & $\begin{array}{c}\text { LHcu } \\
(\mathrm{m})\end{array}$ & $\begin{array}{c}\text { FOB } \\
(\mathrm{N})\end{array}$ & $\begin{array}{c}\text { LTC } \\
(\mathrm{mm})\end{array}$ & $\begin{array}{c}\text { FOCS } \\
(\mathrm{N} / \mathrm{mm})\end{array}$ & $\begin{array}{c}\text { FOC } \\
(\mathrm{N})\end{array}$ \\
\hline 83 & 26 & 10 & 0,696 & 1,5 & 0,606 & 330 & 58 & 224,3 & 112,15 \\
\hline
\end{tabular}

Assim foi encontrada uma força necessária de $112,15 \mathrm{~N}$. Considerando que o torque necessário é dado pela equação:

$$
\mathrm{T}=\text { FOC. } \mathrm{r}
$$$$
\text { Equação } 5
$$

Onde: T é o torque (N. m) FOC é a força de corte $(112,15 \mathrm{~N})$

MS $360(0,03 \mathrm{~m})$.

r é o raio da engrenagem pinhão motoserra Stihl

$$
\mathrm{T}=3,36 \text { N.m. }
$$

Sabendo que os elos da corrente têm que viajar a uma velocidade linear de $10 \mathrm{~m} / \mathrm{s}$, e que no sistema de sabre/corrente de corte da motosserra Still MS360 o raio da engrenagem pinhão é de $0,03 \mathrm{~m}$, tem-se a rotaçáo necessária ao motor elétrico de 333 radianos/s, o que equivale a $3181 \mathrm{rpm}$. A potência do motor elétrico de corte deve ser de $1119 \mathrm{~W}$. O motor elétrico selecionado para atender tais requisitos é um Makita UC 4020 de 1800 W, com rotação nominal de 3200 rpm e voltagem de $110 \mathrm{~V}$, corrente alternada.

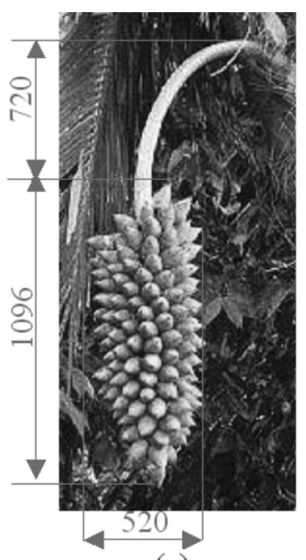

(a)

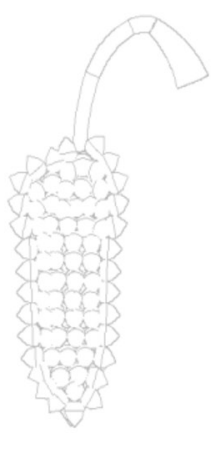

(b)

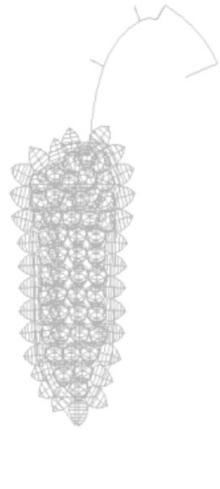

(c)

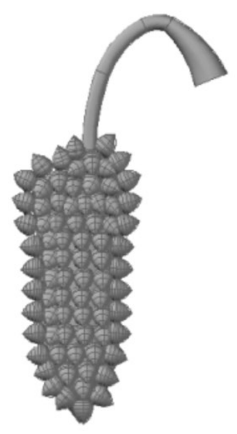

(d)

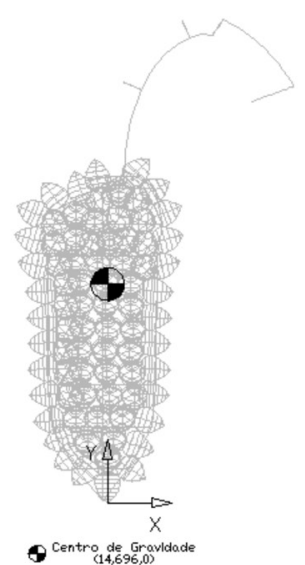

Figura 4 - Cacho de babaçu digitalizado para obtenção do Centro de Gravidade, (a) foto original em escala (mm), (b) digitalização, (c) vetorização, (d) renderização. Centro de Gravidade do cacho de babaçu (14 mm, $696 \mathrm{~mm}, 0)$. 
O sistema de corte foi projetado em função de um sabre de moto-serra Stihl MS360, e de acionamento elétrico através de um motor elétrico, a movimentação do cabeçote de corte será realizada através de três motores elétricos, cada motor em um eixo distinto e ortogonal ao eixo principal do pistáo composto.

\section{Sistema de Hidráulico:}

Para suprir de energia hidráulica necessária ao pistáo hidráulico e as rotaçóes e torques necessários para operar os motores hidráulicos são fornecidos bomba hidráulica será proveniente da TDP do motocultor Bertolini, que possui duas regulagens de rotaçóes (600 e $900 \mathrm{rpm}$ ), foi selecionada a rotação de $600 \mathrm{rpm}$ que disponibiliza $116 \mathrm{~N} . \mathrm{m}$, para atender as especificaçôes da bomba foi projetado um sistema de engrenagens com relaçấo de multiplicação 1:2, o que possibilita uma rotação de $1200 \mathrm{rpm}$ com um torque de 58 N.m, portanto, pelos dados apresentados na Tabela 5, foi possível selecionar a bomba hidráulica Verion NPH 51, que possibilita uma vazáo de 60 litros por minuto e consome 30 N.m da TDP, quando regulada para 35 bar de pressáo.

O pistáo composto totalmente distendido e na pior situação $\left(15\right.$ metros e $\left.30^{\circ}\right)$ tem uma projeção do CG de 1,53 metros, relativo ao torque no eixo vertical da máquina, considerando uma solicitação de uma força ortogonal ao cabeçote de corte e paralela ao solo de $50 \mathrm{kgf}$, na Figura 5 temse um torque no eixo vertical de 765 N.m, o motor hidráulico tem que vencer este torque em toda a faixa de rotação do pistáo composto que estiver sujeito a este torque (p radianos).

Foram selecionados os tempos de ação de cada pistáo e do motor hidráulico, levando-se em conta as características da árvore de babaçu e os babaçuais.

Tabela 5 - Características dimensionais dos pistões e tempos de abertura.

\begin{tabular}{lcccc}
\hline Pistão & $\begin{array}{c}\text { Extensão } \\
(\mathrm{mm})\end{array}$ & $\begin{array}{c}\text { Diâmetro } \\
\text { interno cilindro } \\
\text { (polegadas) }\end{array}$ & $\begin{array}{c}\text { Volume } \\
(\mathrm{I})\end{array}$ & $\begin{array}{c}\text { Tempo para } \\
\text { abertura } \\
\text { total }^{3}(\mathrm{~s})\end{array}$ \\
\hline $\begin{array}{l}\text { Pistão da Pata } \\
\text { direita }\end{array}$ & 500 & 2 & 0,98 & 3 \\
$\begin{array}{l}\text { Pistão da Pata } \\
\text { esquerda }\end{array}$ & 500 & 2 & 0,98 & 3 \\
$\begin{array}{l}\text { Pistão de extensão } \\
\text { da Pata direita }\end{array}$ & 400 & 2 & 0,78 & 3 \\
$\begin{array}{l}\text { Pistão de extensão } \\
\text { da Pata esquerda }\end{array}$ & 400 & 2 & 0,78 & 3 \\
$\begin{array}{l}\text { Pistão de deflexão } \\
\text { do pistão composto }\end{array}$ & 250 & 2 & 0,50 & 5 \\
$\begin{array}{l}\text { Pistão discos } \\
\text { suportes }\end{array}$ & 150 & 2 & 0,29 & 3 \\
$\begin{array}{l}\text { Pistão direção } \\
\text { Pistão composto }\end{array}$ & 140 & 2 & 0,27 & 2 \\
\hline
\end{tabular}

Obs: 1-diâmetro interno do ultimo cilindro suporte para a haste na distensão máxima; 2-diâmetro interno do primeiro cilindro; 3-os tempos de fechamento total serão considerados os mesmos com exceção somente do pistão composto.
Considerando os tempos de abertura total e os volumes que participam das operaçôes, a vazáo necessária à bomba hidráulica será e 60 litros/minuto. Para o cálculo da pressão necessária ao circuito hidráulico é preciso uma análise dos pesos e momentos que o sistema hidráulico deve vencer, a distribuição de pesos estimada para a máquina e a solicitação máxima de projeto no cabeçote de corte em elevação máxima é apresentada na Figura 5.

Foram selecionados os seguintes motores elétricos para atender as solicitaçôes do sistema de movimentação do
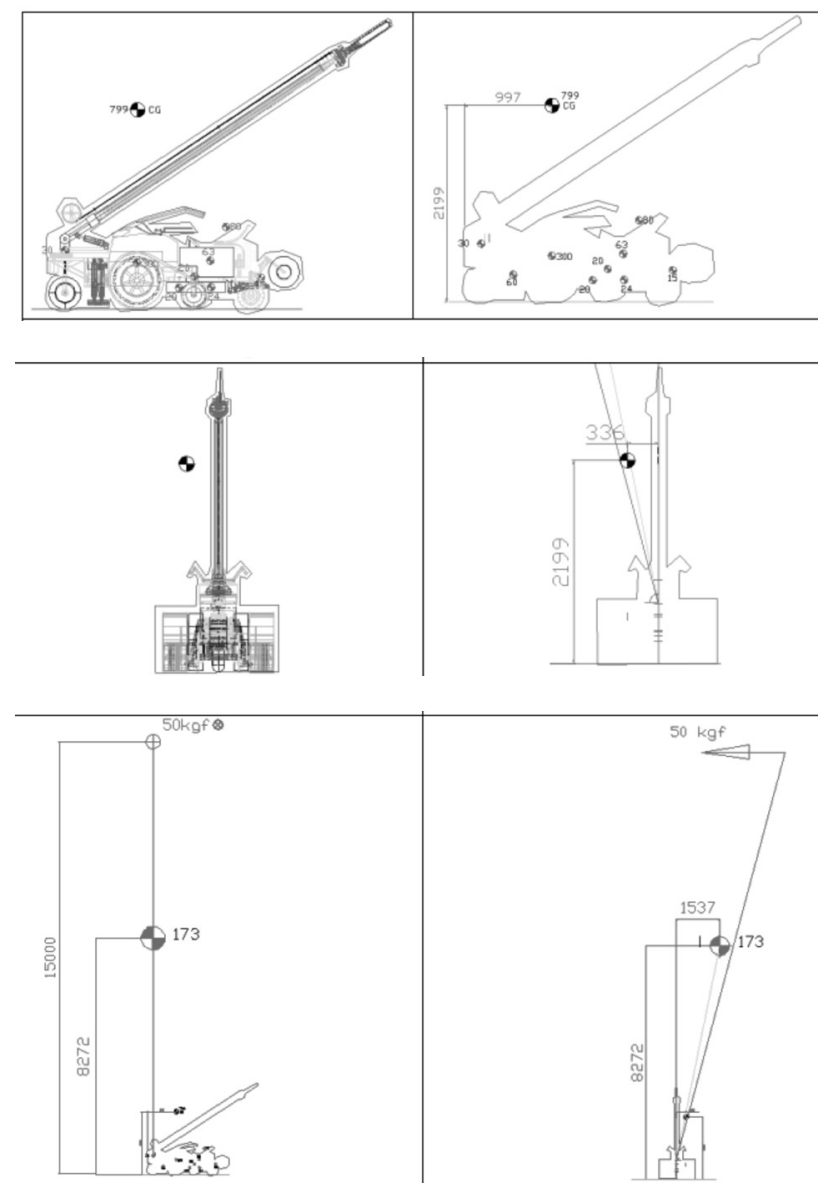

Figura 5 - Distribuição de massas e Centro de Gravidade da colhedora de babaçu, dimensões em mm e kg, Figura 5 (a) símbolo de centro de gravidade cor preta $=\mathrm{CG}$ global da máquina ao lado massa (números pretos) representada (com cilindro composto totalmente elevado na pior situação (declividade $\left.30^{\circ}\right)$ ), símbolo de centro de gravidade cor vermelho $=$ CG parcial da máquina ao lado massa parcial, Figura 5(b) e Figura 5(c) linha vermelha=projeção do pistão composto totalmente distendido, linha verde $=$ projeção do CG parcial do pistão composto.

cabeçote de corte, motores M1, 2 e 3 corrente contínua (cc) e M4 corrente alternada (ca):

O sistema elétrico deverá ser suprido por uma bateria e um alternador, sendo escolhida uma bateria Tudor de 90 
Tabela 4 - Motores elétricos selecionados para o cabeçote de corte

\begin{tabular}{llllllll}
\hline Motor & Modelo & $\begin{array}{l}\text { Potência } \\
(\mathrm{W})\end{array}$ & Torque (N.m) & Rotação (rpm) & Voltagem (V) & Amperagem (A) & Peso (kg) \\
\hline M1 & Bosch CHP & 12 & 3,5 & 38 & 12 & 1 & 1,1 \\
M2 & Bosch CEP & 28 & 8 & 26 & 12 & 2,3 & 1,1 \\
M3 & Bosch CEP & 28 & 8 & 26 & 12 & 2,3 & 1,1 \\
M4 & Makita UC4020 & 1800 & 3,36 & 3200 & 110 & 8,8 & 4 \\
\hline
\end{tabular}

Ah a $12 \mathrm{~V}$ de capacidade de suprimento de energia, o que subentende a necessidade de uma bobina elevadora para elevar a tensão de $12 \mathrm{~V}$ para $110 \mathrm{~V}$ com uma corrente de $8,8 \mathrm{~A}$, assim como um inversor de freqüência, devido à necessidade do motor Makita.

O circuito elétrico para o cabeçote de corte é apresentado na Figura 6.

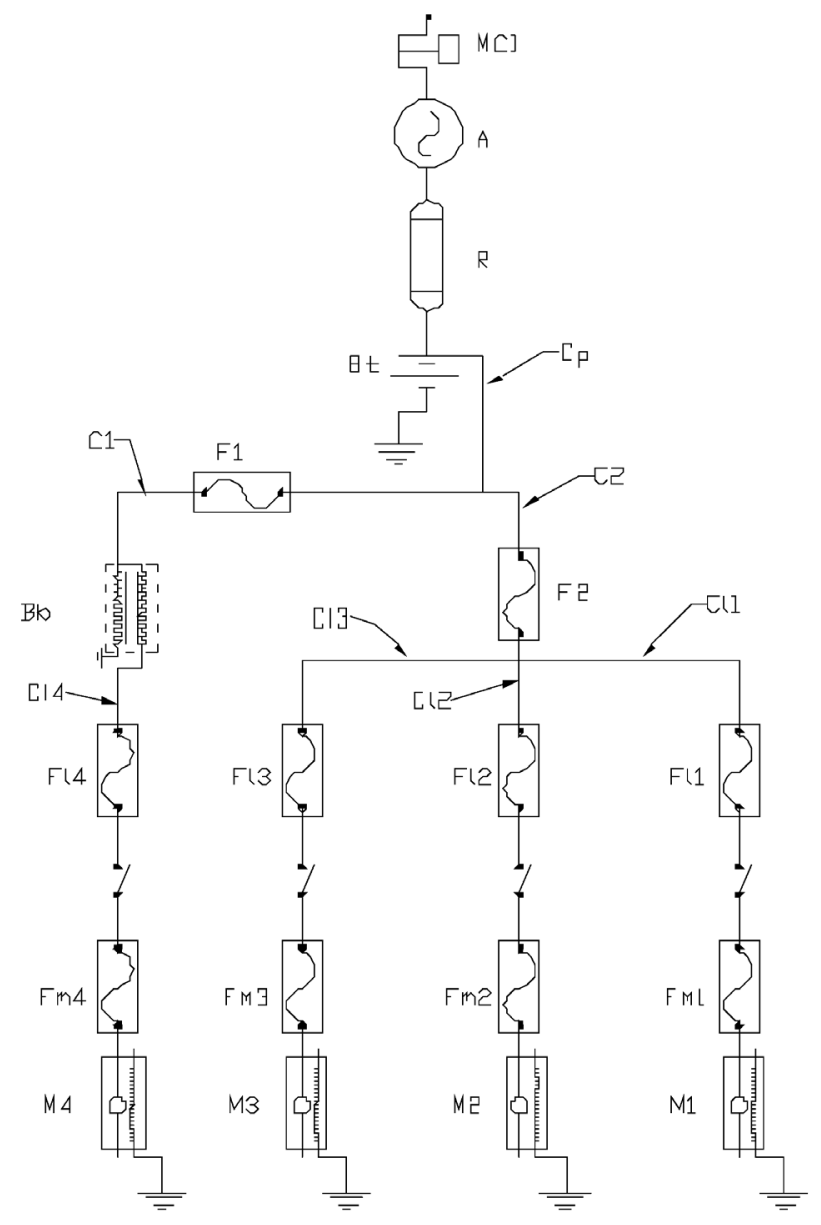

Figura 6 - Diagrama elétrico do cabeçote de corte.

\section{RESULTADOS}

\section{Desenho Global da Colhedora de Babaçu}

Em funçáo do conceito detalhado proposto por Albiero et al. (2007) e das modificaçôes perpetradas a vista dos estudos de literatura e dos conseqüentes cálculos foram realizados os desenhos globais da colhedora de babaçu, Figura 7 e Figura 8.

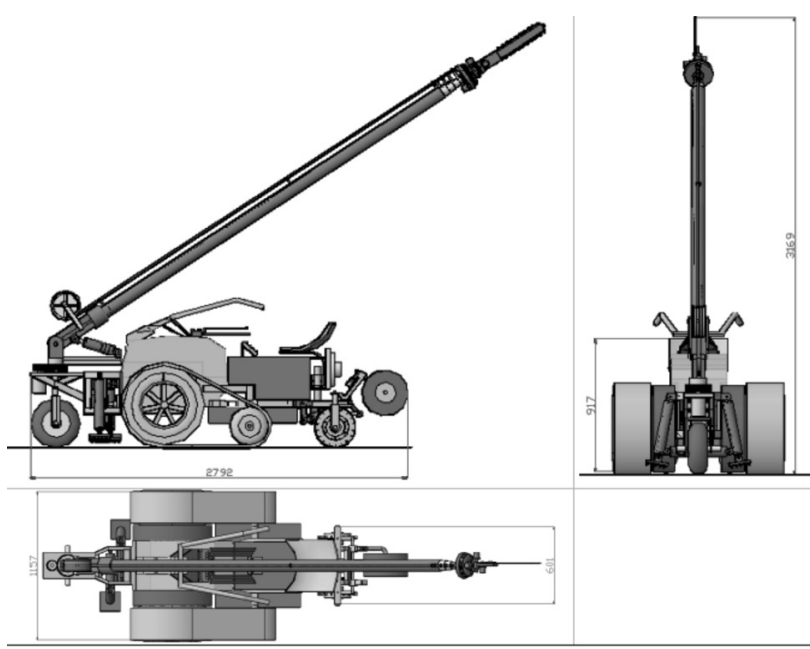

Figura 7 - Três vista do anteprojeto da colhedora de babaçu.

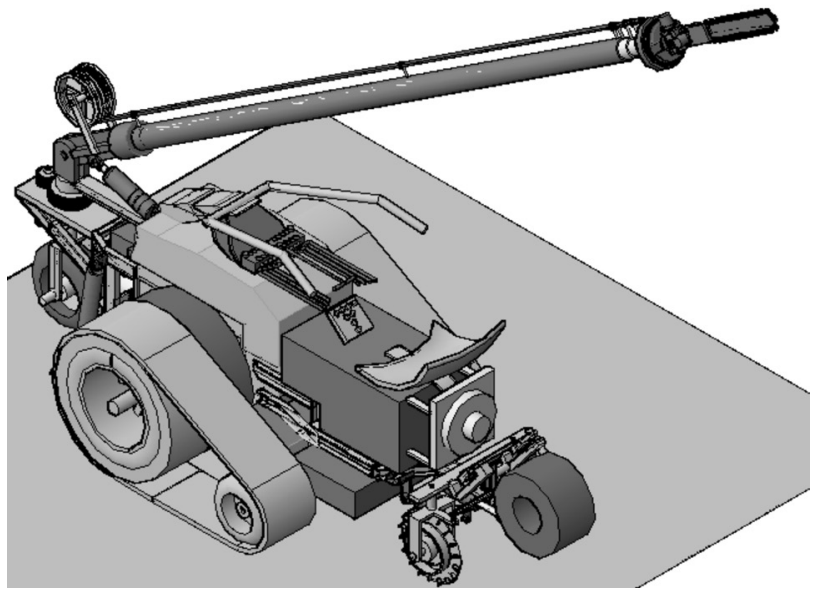

Figura 8 - Perspectiva do anteprojeto da colhedora de babaçu. 


\section{Sistema de Corte}

O sistema de corte foi projetado segundo os cálculos e possuí a configuração apresentada na Figura 9.
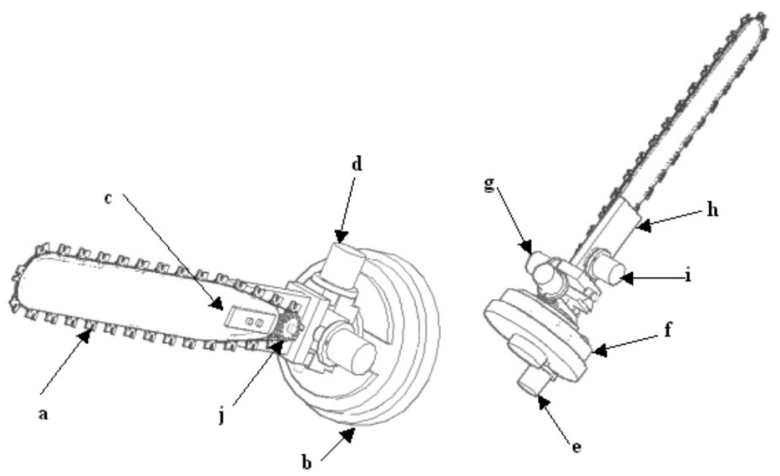

Figura 9 - Cabeçote de corte elétrico da colhedora de babaçu, (a) corrente de Stihl Duromatic 50, (b) suporte fixo do cabeçote no pistão, (c) sabre de Stihl Duromatic $50 \mathrm{~cm}$, (d) motor elétrico de rotação transversal-M2, (e) motor elétrico de rotação zenital-M1, (f) engrenagem cremalheira interna, (g) motor elétrico de rotação longitudinal-M3, (h) suporte do sabre, (i) motor elétrico da corrente-M4; (j) engrenagem pinhão da corrente de corte.

Para a fiação chegar até o topo do cabeçote de corte foi projetada uma roldana com mola espiral para comportar a fiação, Figura 10.

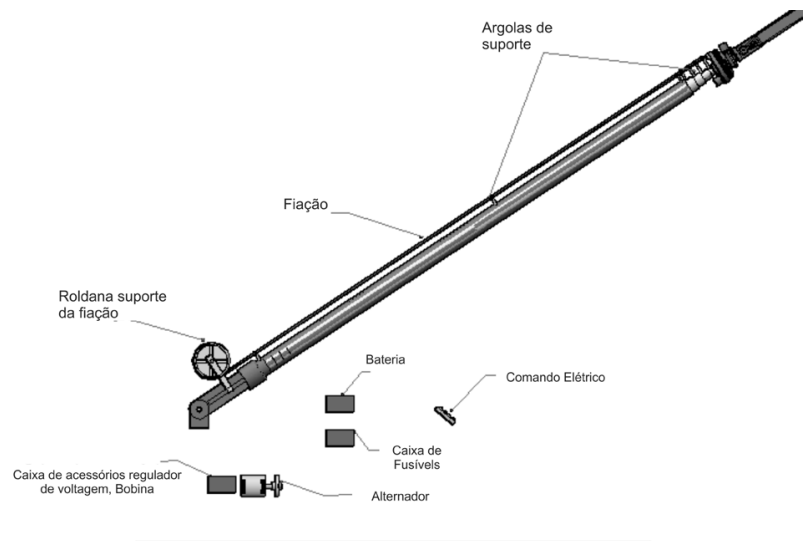

Figura 10 - Sistema elétrico da colhedora de babaçu.

\section{Sistema Hidráulico e de Equilíbrio}

Pelo anteprojeto da colhedora de babaçu apresentado na Figura, tem-se um sistema hidráulico formado por 7 pistóes de dupla açáo, um pistáo composto, um comando hidráulico de 9 elementos, 3 tanques de óleo hidráulico, um radiador de óleo, uma bomba hidráulica, um motor hidráulico, tubos, mangueiras, conexóes e filtros, Figura 11.

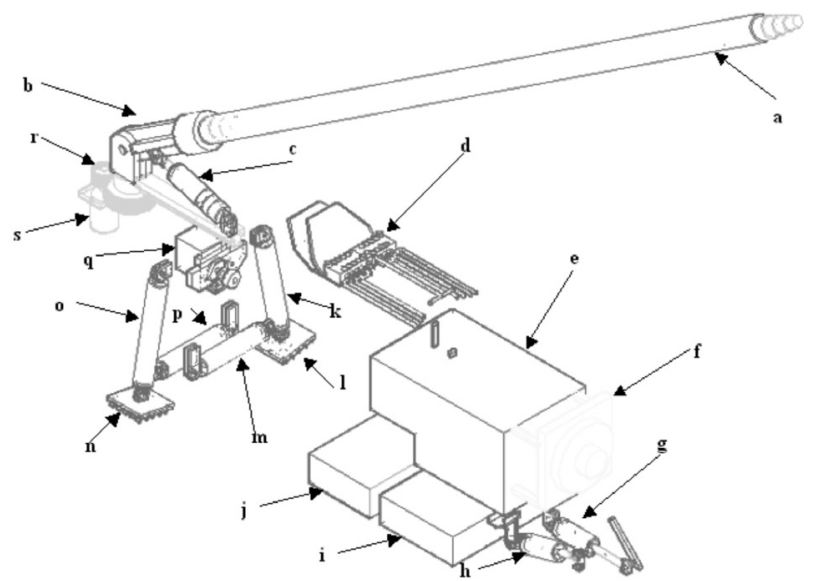

Figura 11 - Sistema hidráulico da colhedora de babaçu, vista posterior, (a) pistão composto, (b) suporte e válvula elétrica do pistão composto, (c) pistão de deflexão do pistão composto, (d) comando hidráulico de 9 elementos, (e) tanque principal de óleo hidráulico, (f) radiador de óleo hidráulico e ventilador, (g) pistão de acionamento dos discos suportes de direção, (h) pistão de direção, (i) tanque auxiliar 2, (j) tanque auxiliar 1, (k) pistão da pata direita, (l) pata direita, (m) pistão de extensão da pata direita, (n) pata esquerda, (0) pistão da pata esquerda, (p) pistão de extensão da pata esquerda, (q) bomba hidráulica, (r) engrenagens sistema de rotação pistão composto, (s) motor hidráulico.

\section{Chassi}

O chassi foi projetado visando o menor peso da estrutura e a maior resistência, Figura 12.

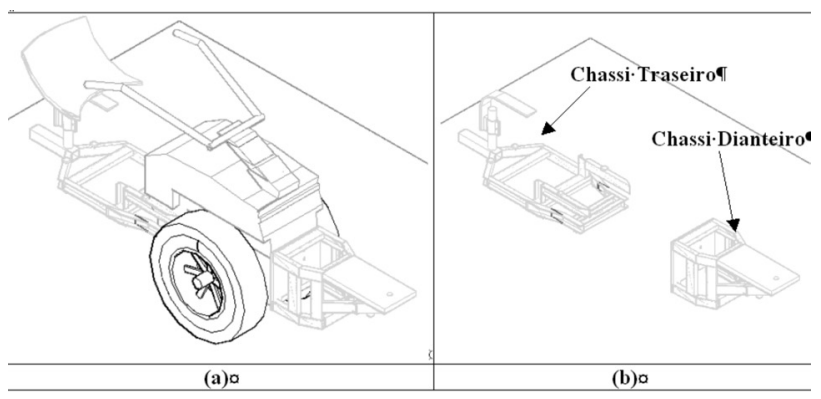

Figura 12 - Chassi da colhedora de babaçu, (a) acoplado ao Bertolini 318, (b) chassi.

Levando em conta as solicitaçóes da Figura 13 e 14, foram calculadas as estruturas do chassi para suportarem as solicitaçóes impostas, através do software Ansys 9.0 ED (2004).
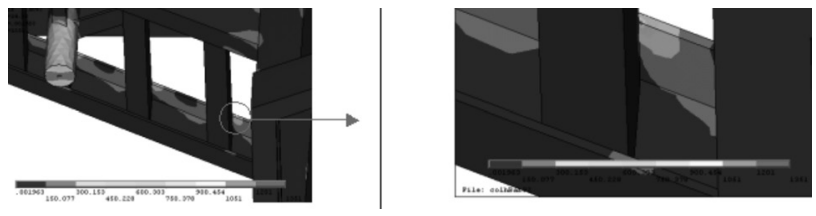

Figura 13 - Cálculo estrutural do chassi frontal da colhedora de babaçu, marca circular vermelha indica ponto de máxima tensão de von Mises. 
Foi utilizada como elemento estrutural vigas U de 2" de aço 1020. A máxima tensão de von Mises se encontra no chassi frontal em um ponto de concentração de tensão localizado entre uma viga de travamento lateral da estrutura e uma longarina diagonal, seu valor calculado foi de $1351 \mathrm{kgf} /$ $\mathrm{cm}^{2}(135,1 \mathrm{MPa})$, a tensão de escoamento do aço 1020 é de $210 \mathrm{MPa}$, portanto a estrutura suporta a solicitação máxima aplicada, com um fator de segurança de 1,55, cabe lembrar que a solicitaçấo de $50 \mathrm{kgf}$ na ponta do cabeçote de corte com o pistão totalmente distendido $(15 \mathrm{~m})$ é superdimensionada, visto a válvula de alívio do sistema hidráulico ser regulada para atuar à aplicação de uma força de $25 \mathrm{kgf}$.
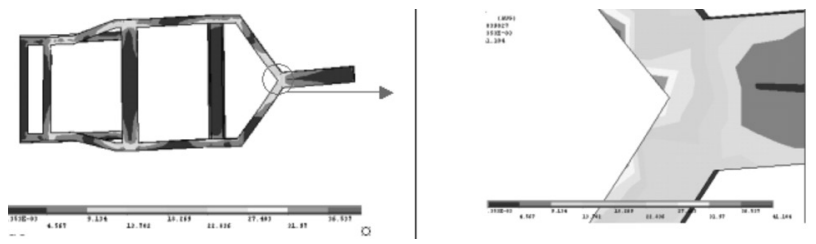

Figura 14 - Cálculo estrutural do Chassi traseiro, marca circular vermelha indica ponto de máxima tensão de von Mises

Pela Figuras 13 e 14 percebe-se que o aço 1020 é suficiente para as solicitaçốes atuantes, visto a máxima tensão de von Mises ser de $41 \mathrm{kgf} / \mathrm{cm}^{2}$, muito inferior à capacidade do aço $1020\left(2100 \mathrm{kgf} / \mathrm{cm}^{2}\right)$.

\section{Sistema de Locomoção/Sistema de Direção}

Com objetivo de aumentar a área de contato do sistema de locomoção e melhorar a dirigibilidade da colhedora de babaçu em área com grande teor de água no solo, foi projetado: sistema de esteiras, direção e suporte para manobras apresentados na Figura 15.

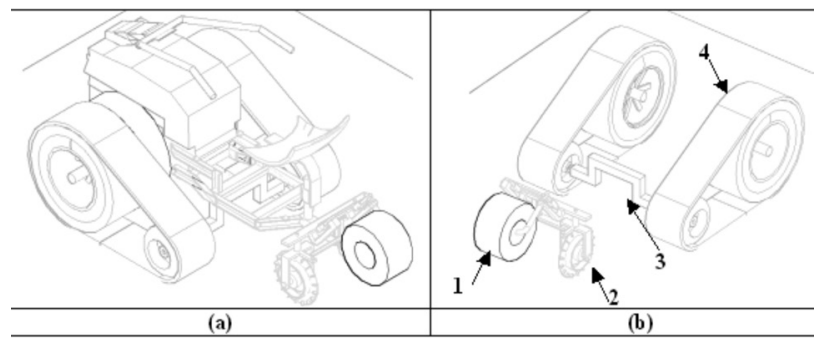

Figura 15 - Sistema de suporte, direção e locomoção da colhedora de babaçu, (a) acoplado ao motocultor e ao chassi traseiro, (b) (1) roda de direção, (2) disco de suporte para a direção, (3) eixo principal do sistema de esteiras, (4) esteira de borracha, largura de $250 \mathrm{~mm}$.

A área total de suporte das esteiras, da roda de direçáo, e da roda de suporte (frontal) é de $0,7 \mathrm{~m}^{2}$, considerando o peso estimado da colhedora como de $8000 \mathrm{~N}$, tem-se uma tensão sobre o solo de $11428 \mathrm{~N} / \mathrm{m}^{2}$ (11,42 kPa). Pela Tabela 1 , tem-se para $40 \%$ de teor de água no solo uma tensão de pré-consolidação de $19 \mathrm{kPa}$, portanto a colhedora de babaçu, até um valor pouco acima de $40 \%$ de teor de água no solo pode se deslocar no solo florestal sem compactá-lo. Em relaçáo ao problema do afundamento das esteiras e rodas no solo pela Equação 4 e Tabela 2, foi possível calcular para a tensão (considerando o teor de água de $40 \%$ ) imposta ao solo pela nova máquina, o afundamento que foi de $2,3 \mathrm{~cm}$, sempre considerando o plintossolo como solo suporte, para tal afundamento não ocorre o perigo de atolamento da máquina, conseqüentemente é viável a locomoção pelos babaçuais. Cabe lembra que o valor de $40 \%$ de teor de água no solo é um limite para períodos úmidos, nos meses de seca, este valor será menor.

\section{DISCUSSÃO}

Um dos gargalos técnicos da produção do babaçu é a colheita feita de forma manual e no sistema extrativista (Zylbersztajn et al., 2000) e uma forma de melhorar este elo da cadeia produtiva do babaçu é desenvolver o conceito de uma colhedora de babaçu moto-mecanizada capaz de trabalhar em florestas naturais (Albiero et al., 2007).

Neste contexto, tecnicamente, este projeto da colhedora de babaçu para atuar em florestas nativas é altamente viável e possibilitará um alívio na situação social e ambiental dos babaçuais amazônicos, de cerrado e de caatinga, possibilitando a agricultora familiar destas regiôes uma melhoria das condiçóes de trabalho e renda, sem a necessidade de desmatamento, pois a nova colhedora tem capacidade operacional de transitar por entre florestas nativas e babaçuais extremamente densos. As dimensôes da nova máquina são compatíveis com a de um animal de carga (burro ou mula) de tal forma que da mesma forma que um animal se locomove por entre árvores próxima, a nova colhedora também é capaz de fazer. Teixera (2002) descreve que atualmente a coleta dos cocos de babaçu é realizada manualmente com o auxílio de um burro ou mula para carregar a carga, assim para projetos futuros é possível pensar em uma recolhedora de babaçu montada em outro motocultor, para complementar o trabalho da colhedora.

Novas tecnologias de processamento e novos desenhos de produtos e processos são de fundamental importância para garantir qualidade e atrair compradores nos países desenvolvidos, possibilitando a manutenção da floresta amazônica (Clement \& Higuchi, 2006). A nova colhedora tem aspectos de projeto inovadores, tanto em termos de mecanismos e sistemas (sistema de cabeçote de corte elétrico elevado por cilindro hidráulico composto) como conceituais (máquina capaz de transitar por entre florestas nativas encharcadas) que visaram a otimização do sistema procurando o melhor ponto de equilíbrio entre eficiência operacional e respeito a mata. O sistema de locomoçâo através de esteira minimiza o dano ao solo devido a compactação proveniente do peso da máquina, e o sistema de direção composto por 
discos e rodas possibilita a mudança da configuração de transporte em ambiente seco para configuração de trabalho em ambiente úmido.

No caso de utilização desta nova máquina em outras regióes com aspectos de solo e densidade de plantas diferentes percebe-se que não existem problemas, pois em termos de solos a máquina foi projetada considerando a pior situação para locomoção e compactação (solos hidromórficos com alta umidade), já em termos de densidade de plantas por hectare tem-se um projeto que atingiu o limite de tamanho considerando-se motocultores, assim qualquer mata com densidade maior tem difícil acesso até para pessoas e animais, sempre considerando que foi utilizada a distribuição log-normal para abundância de plantas, que é a melhor distribuição para comunidades ecológicas com abundância intermediária e poucas espécies com abundâncias muito altas ou muito baixas (Ferreira, 1999).

\section{CONCLUSÃO}

O desenvolvimento e projeto da colhedora de babaçu adaptável ao ambiente de trabalho da agricultura familiar e as características das matas de transição amazônicas foi concluído com sucesso. O memorial de cálculo do projeto, os desenhos e as simplificaçóes adotadas são apresentadas e descritas.

Pelas consideraçôes e decisôes tomadas esta nova máquina apresenta-se passível de ser construída com materiais nacionais de baixo custo, além de apresenta-se de fácil operação, manutenção e com mínimo efeito sobre os babaçuais naturais.

\section{AGRADECIMENTOS}

Ao Conselho Nacional de Desenvolvimento Científico e Tecnológico (CNPq) pela bolsa de doutorado do primeiro autor.

\section{BIBLIOGRAFIA CITADA}

Albiero, D.; Maciel, A. J. S; Lopes, O. C.; Mello, C. A.; Gamero, C. A. 2007. Proposal of Machine for babaçu (Orbignya phalerata Mart.) harvest for small farms. Acta Amazônica, 37 (3): 337 346 (in Portuguese, with abstract in English).

Alencar, F. H.; Yuyama, L. K. O.; Varejão, M. J. C.; Marinho, H. A. 2007. Decisive and consequences of the alimentary insecurity in Amazonas: the influence of the ecosystems. Acta Amazônica, 37 (3): 413 - 418 (in Portuguese, with abstract in English).

ANSYS, Inc. 2004. Ansys 9.0 ED.

Clement, C. R.; Higuchi, N. 2006. The Amazon jungle and the Brazil of future. Ciência e Cultura, 58 (3): 25-37 (in Portuguese, with abstract in English).

Clement, C. R.; Lleras Peres, E.; van Leeuwen, J. 2005. The potential of the tropical palm trees in Brazil: Successes and failures of the last decades. Agrociencias, 9, (1-2): 67-71. (in Portuguese, with abstract in English).
Dias Junior, M. S.; Fonseca, S.; Araújo Júnior, C. F.; Silva, A. R. 2007. Soil compaction due to forest harvest operations. Pesquisa Agropecuária Brasileira, 42 (2): 257 -264.

EMBRAPA. 1999. Brazilian system of Classification of Soils. Empresa Brasileira de Pesquisa Agropecuária, Brasília. 320 pp (in Portuguese).

Emmerich, F. G. 1987. Model to granulate, percolation-resistivity, $R S E$ and module of elasticity of carbon materials: Application to the endocarp of babaçu termically treated up to 3200 oC. Tese de Doutorado, Universidade Estadual de Campinas, Campinas. 181 pp (in Portuguese).

Ferreira M. E. M. 1999. Log-normal models and markovian for study of the abundance evolution in a babaçu forest. Dissertação de mestrado, Universidade Federal de Santa Catarina, Florianópolis. 126 pp (in Portuguese).

Hueck, K. 1972. The jungles of South America. Editora da Universidade de Brasília, Brasília. 466 pp (in Portuguese).

IBGE. 2008. Soil Maps Brazil. <http://mapas.ibge.gov.br/solos/ viewer.htm>, accessed in 20/05/2008 (in Portuguese).

Leonardo, F. S.; Rebelo, J. M. M. 2004. The perimetral urbanization of Lutzomyia whitmani in area of focus of cutaneous leishmaniose, in the State of Maranhão, Brazil. Revista da Sociedade Brasileira de Medicina Tropical, 37 (3): 282 - 284 (in Portuguese, with abstract in English).

May, P. H. 1990. Palm tree in flames: Agrarian transformation and social justice in the babaçu zone. EMAPA/FINEP/ Fundação Ford, São Luis. 240 pp (in Portuguese).

May, P.; Veiga Neto, F. C.; Cheves Pozo, O. V. 2000. Economic value of biodiversity. Ministério do Meio Ambiente, Brasília. (in Portuguese).

Mitchell, J. K. 1993. Fundamentals of soil behavior. John Wiley \& Sons, New York. 437 pp.

Morais, D. S.; Neves, O.N.E.; Dias, C.G.B.T. 2006. Analysis of the mechanical properties of biodegradable composites to the pectina/eva base reinforced with coconut fiber. In: Congresso Brasileiro de Engenharia e Ciência dos Materiais, 17º, Anais... Foz do Iguaçu: CBECIMat. 9 pp (in Portuguese, with abstract in English).

Nascimento, U. S. 2004. Babaçu coal as thermal source for system of refrigeration for absorption in the State of Maranhão. Dissertação de Mestrado, Universidade Estadual de Campinas, Campinas. 100 pp (in Portuguese).

Persson, S. 1987. Mechanics of cutting plant material. American society of agricultural engineers, St. Joseph. $288 \mathrm{pp}$.

Savastano Junior, H.; Agopyan, V.; Oliveira, L. 1997. Study of the microstructure of the vegetable fibers and of its implications on the acting of composites cements. Engenharia Agricola, 17 (1): 113-124 (in Portuguese, with abstract in English).

Teixeira, M. A. 2002. Babaçu biomass in Brazil. In: AGRENER 2002. Anais...Campinas. NIPE-UNICAMP. 210-220 (in Portuguese, with abstract in English).

Upadhyaya, S. K.; Chancellor, W. J.; Perumpral, J. V.; Schafer, R. L.; Gill, W. R.; Vanden erg, G. E. 1994. Advances in soil dynamics. American society of agricultural engineers . St. Joseph. 313 pp. 


\section{ACTA}

USP. 2006. Babaçu. <http://www.bibvirt.futuro.usp.br >, acessado em 20/05/2006 (in Portuguese).

Zylbersztajn, D.; Marque, C. A. S.; Nassar, A. M.; Pinheiro, C. M.; Martinelli, D. P.; Adeodato A. Neto, J.; Marino, M. K.; Nunes, R. 2000. Reorganization of the agribusiness of the babaçu in the state of Maranhão. Relatório técnico. Grupo Pensa-USP, São Paulo. 120 pp (in Portuguese).

Recebido em 15/12/2008

Aceito em 07/02/2010 
